\title{
Perancangan Sistem Informasi Pengolahan Data Korban Bencana pada Badan Penanggulangan Bencana (BPBD)
}

\author{
RAHMAD SETYO ADI \\ 165100111, 785567936 \\ Fakultas Komputer \\ rahmadsetyoadi.student@umira.ac.id
}

\begin{abstract}
Badan Penanggulangan Bencana Daerah (BPBD) merupakan sebuah Lembaga Pemerintah yang mempunyai tugas untuk membantu mengkoordinasikan perencanaan dan pelaksanaan kegiatan penanganan bencana dan kedaruratan secara terpadu, Saat ini BPBD dalam melaksanakan proses pendataan korban bencana masih lambat yang disebabkan karena masih memprosesnya secara manual. Dalam melakukan proses pendataan di setiap posko pengungsi kemungkinan masih terjadinya kesulitan antara lain, perhitungan yang kurang akurat dan waktu yang cukup lama dalam pengolahan data. Tujuan Penelitian ini membuat sistem informasi pengolahan data korban bencana Pada BPBD. Agar mempermudah admin mengelola data bencana pada BPBD. Metode Pengumpulan data yang digunakan yaitu observasi, wawancara, studi kepustakaan. Alat bantu rancangan menggunakan Flowchart, DFD, ERD dan bahasa pemrograman Borland Delphi 7, dengan adanya sistem ini dapat mempermudah admin dalam mengelola data bencana serta meningkatkan kinerja pelayanan pada BPBD
\end{abstract}

Kata kunci: Perancangan, Sistem Informasi, Korban Bencana 


\section{UAS - 88675543}

\section{A. INTRODUCTION}

Pada saat ini komputer memegang peranan penting dalam suatu pekerjaan serta dapat meningkatkan kualitas dan kuantitas pekerjaan tersebut. Banyak pekerjaan yang dilakukan pada setiap instansi maupun organisasi dapat berjalan

komputer sebagai alat bantu

Dengan media komputer dapat memberikan manfaat dalam pengelolaan data, jika hal tersebut dapat dimanfaatkan dan dibuat dalam sebuah sistem agar lebih efisien dan mudah dalam mengelola data tersebut untuk menghasilkan informasi 
C. yang dibutuhkan oleh instansi maupun organisasi untuk mencapai sautu tujuan, Untuk itu, diperlukan suatu sistem informasi yang baik, dimana sistem informasi tersebut merupakan suatu dukungan yang dapat memberikan pelayanan terhadap permasalahan yang dihadapi perusahaan swasta maupun instansi pemerintah. Salah satunya yang terjadi pada Badan Penanggulangan Bencana Daerah (BPBD)

Badan Penanggulangan Bencana Daerah (BPBD) merupakan sebuah Lembaga Pemerintah yang mempunyai tugas untuk membantu mengkoordinasikan perencanaan dan pelaksanaan kegiatan penanganan bencana dan kedaruratan secara terpadu, serta melaksanakan penanganan bencana dan kedaruratan mulai dari sebelum, pada saat, dan setelah terjadi bencana yang meliputi pencegahan, kesiap siagaan, penanganan darurat, dan pemulihan

Saat ini BPBD dalam melaksanakan proses pendataan korban bencana masih lambat yang disebabkan karena, masih memprosesnya secara manual. Dalam melakukan proses pendataan di posko posko pengungsi kemungkinan masih terjadinya kesulitan antara lain, perhitungan yang kurang akurat

dan waktu yang cukup lama dalam pengolahan data.

Hengan dipertimbangan dan permasalahan diatas, maka perlu membangun dan menerapkan satu sistem informasi yang mengelola Pata Korban Bencana di BPBD Menggunakan Bahasa Pemograman Borland Delphi”. Dengan dukungan dengan IBEasy + sebagai database server dan Program Crystal Report sebagai Form laporan yang siap untuk di cetak (print).

\section{B. CONTENT}

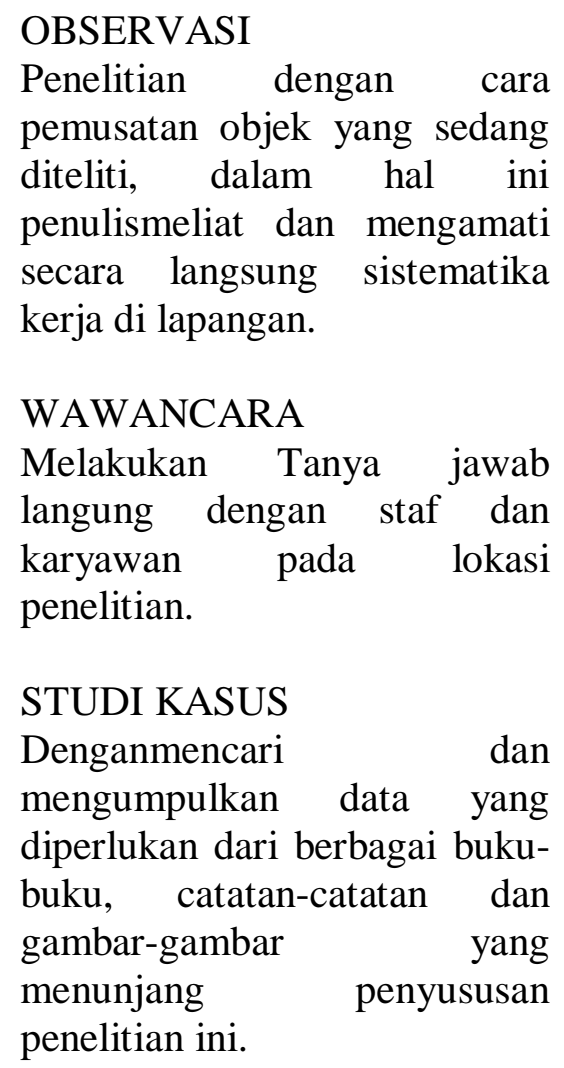




\section{CONCLUSION}

1. Pengolahan data korban bencana BPBD dapat mempermudah admin dalam mengolah data bencana pada system secara cepat.

2. Berdasarkan hasil uji coba program yang baru dirancang dengan mengimput salah satu data atau tabel misalnya data bencana hanya membutuhkan kurang 5 menit data tersebut sudah selesai diinput dan dicetak sebagai laporan.

\section{DISCUSSION}

1. Diharapkan pada kantor BPBD khususnya pada admin atau melakukan penelitian computer yang diadakan oleh lembaga pendidikan.

2. Untuk akamedi perlu memperbanyak

pengawasan atau bimbingan ahli program agar memproleh hasil yang maksimal dari suatu program tersebut. 


\section{E. REFERENCE}

[1] O. M. Febriani and A. S. Putra, "Sistem Informasi Monitoring Inventori Barang Pada Balai Riset Standardisasi Industri Bandar Lampung," J. Inform., vol. 13, no. 1, pp. 90-98, 2014.

[2] A. S. Putra, "Paperplain: Execution Fundamental Create Application With Borland Delphi 7.0 University Of Mitra Indonesia," 2018.

[3] A. S. Putra, "2018 Artikel Struktur Data, Audit Dan Jaringan Komputer," 2018.

[4] A. S. Putra, "ALIAS MANAGER USED IN DATABASE DESKTOP STUDI CASE DB DEMOS."

[5] A. S. Putra, "COMPREHENSIVE SET OF PROFESSIONAL FOR DISTRIBUTE COMPUTING."

[6] A. S. Putra, "DATA ORIENTED RECOGNITION IN BORLAND DELPHI 7.0."

[7] A. S. Putra, "EMBARCADERO DELPHI XE 2 IN GPUPOWERED FIREMONKEY APPLICATION."

[8] A. S. Putra, "HAK ATAS KEKAYAAN INTELEKTUAL DALAM DUNIA TEKNOLOGY BERBASIS REVOLUSI INDUSTRI 4.0.”
[9] A. S. Putra, "IMPLEMENTASI PERATURAN PERUNDANGAN UU. NO 31 TAHUN 2000 TENTANG DESAIN INDUSTRI BERBASIS INFORMATION TECHNOLOGY."

[10] A. S. Putra, "IMPLEMENTATION OF PARADOX DBASE."

[11] A. S. Putra, "IMPLEMENTATION OF TRADE SECRET CASE STUDY SAMSUNG MOBILE PHONE."

[12] A. S. Putra, "IMPLEMENTATION PATENT FOR APPLICATION WEB BASED CASE STUDI WWW. PUBLIKLAMPUNG. COM."

A. S. Putra, "IMPLEMENTATION

SYSTEM FIRST TO INVENT IN DIGITALLY INDUSTRY."

[14] A. S. Putra, "MANUAL REPORT \& INTEGRATED DEVELOPMENT

ENVIRONMENT BORLAND DELPHI 7.0."

[15] A. S. Putra, "PATENT AS RELEVAN SUPPORT RESEARCH."

[16] A. S. Putra, "PATENT FOR RESEARCH STUDY CASE OF APPLE. Inc."

[17] A. S. Putra, "PATENT PROTECTION FOR APPLICATION INVENT."

[18] A. S. Putra, "QUICK REPORT IN PROPERTY PROGRAMMING."

[19] A. S. Putra, "REVIEW CIRCUIT LAYOUT COMPONENT 


\section{REQUIREMENT ON ASUS NOTEBOOK."}

[20] A. S. Putra, "REVIEW TRADEMARK PATENT FOR INDUSTRIAL TECHNOLOGY BASED 4.0."

[21] A. S. Putra, "TOOLBAR COMPONENT PALLETTE IN OBJECT ORIENTED PROGRAMMING."

[22] A. S. Putra, "WORKING DIRECTORY SET FOR PARADOX 7."

[23] A. S. Putra, "ZQUERY CONNECTION

IMPLEMENTED

PROGRAMMING STUDI CASE PT. BANK BCA Tbk."

[24] A. S. Putra, D. R. Aryanti, and I. Hartati, "Metode SAW (Simple Additive Weighting) sebagai Sistem Pendukung Keputusan Guru Berprestasi (Studi Kasus: SMK Global Surya)," in Prosiding Seminar Nasional Darmajaya, 2018, vol. 1, no. 1, pp. 85-97.

[25] A. S. Putra and O. M. Febriani, "Knowledge Management Online Application in PDAM Lampung Province," in Prosiding International conference on Information Technology and Business (ICITB), 2018, pp. 181-187.

[26] A. S. Putra, O. M. Febriani, and B. Bachry, "Implementasi Genetic Fuzzy System Untuk Mengidentifikasi Hasil Curian Kendaraan Bermotor Di Polda Lampung," SIMADA (Jurnal Sist. Inf. dan Manaj. Basis Data), vol. 1, no. 1, pp. 21-30, 2018.

[27] A. S. Putra, H. Sukri, and K.
Zuhri, "Sistem Monitoring Realtime Jaringan Irigasi Desa (JIDES) Dengan Konsep Jaringan Sensor Nirkabel," IJEIS (Indonesian J. Electron. Instrum. Syst., vol. 8, no. 2, pp. 221-232.

[28] D. P. Sari, O. M. Febriani, and A. S. Putra, "Perancangan Sistem Informasi SDM Berprestasi pada SD Global Surya," in Prosiding Seminar Nasional Darmajaya, 2018, vol. 1, no. 1, pp. 289-294. 